\title{
Chromosomal Mosaicism in Diagnostic Amniotic Fluid Cell Cultures
}

\author{
David M. Cox, ${ }^{[25]}$ Virginia Niewczas-Late, Margaret I. Riffell, and John L. Hamerton \\ Department of Paediatrics, University of Manitoba, and Genetics Department, Children's Centre, Health Sciences Centre, \\ Winnipeg, Manitoba, Canada
}

\begin{abstract}
Extract
The occurrence of chromosomal mosaicism in 48 amniotic fluid cell cultures was studied. Chromosome preparations were made by in situ processing and the karyotype was established from the analysis of a series of discrete colonies, thereby reflecting more closely the chromosomal status of the original fluid sample. In $50 \%$ of cultures there were one or more colonies in which the chromosomes were entirely tetraploid, the frequency ranging from $2 \%$ to $14 \%$. No chromosomally abnormal infants were born in these cases and tetraploidy should not be considered a reason for termination of pregnancy. Four amniotic fluid samples showed one, and in one instance two, chromosomally abnormal colonies in cultures with otherwise normal chromosomes. Three of these involved trisomy $(47, \mathrm{XY},+\mathrm{C} ; 47, \mathrm{XX},+\mathrm{C} ; 47, \mathrm{XY},+2)$ and two involved translocation $(46, \mathrm{XY}, \mathrm{t}(\mathrm{Bq}+; \mathrm{Cq}-) ; 46, \mathrm{XX}, \mathrm{t}(2 \mathrm{p}-; \mathrm{Eq}+))$. In no instance did the minor aberrant cell type observed in the amniotic fluid appear in the neonate. The frequency with which chromosomally aberrant cell types appear in normal amniotic fluid cell cultures makes prenatal diagnosis of a true mosaic extremely hazardous.
\end{abstract}

\section{Speculation}

Cultured amniotic fluid cells proliferate as discrete colonies from which chromosome preparations can be obtained using in situ processing. By karyotype analysis of a series of colonies arising from a specimen of amniotic fluid, the interpretation of chromosomal mosaicism, when present, should be rendered less ambiguous.

\section{Introduction}

Chromosomal analysis of fetal cells cultured from amniotic fluid obtained by amniocentesis has gained widespread application for the prenatal determination of the fetal karyotype [14, 15]. The use of this procedure, followed by therapeutic abortion of the chromosomally unbalanced fetus, should reduce the incidence of chromosome defects, particularly Down's syndrome, in the population [2]. That this has come about is largely a result of the general acceptance of transab- dominal amniocentesis as a comparatively safe procedure [5], along with the improved success rate for obtaining chromosome preparations from amniotic fluid cells [16].

With the rapidly increasing use of prenatal chromosome analysis, it has become apparent that the interpretation of the cytogenetic observations, which is generally assumed to be straightforward, may not always be a simple matter. In particular, the presence of mosaicism in amniotic fluid cultures, involving tetraploidy, aneuploidy, or translocation, has been the 
cause of some dilemma $[10,11]$ and controversy $[6,8$, 12]. In this paper, the occurrence of chromosomal mosaicism in a small series of diagnostic amniotic fluid cell cultures is documented and discussed.

\section{Materials and Methods}

Amniotic fluid for prenatal chromosome analysis was obtained by transabdominal amniocentesis between 14 and 20 weeks gestation. Five to $15 \mathrm{ml}$ fluid was withdrawn from each patient and set up in culture the same day. After mixing the amniotic fluid thoroughly, $1-\mathrm{ml}$ aliquots were pipetted into a series of $60-\mathrm{mm}$ plastic petri dishes [20] each containing $3 \mathrm{ml}$ McCoy's 5 a modified tissue culture medium [21] supplemented with $10 \%$ fetal bovine serum [22] and 5\% human cord serum. The dishes were agitated and then incubated at $37^{\circ}$ in a $100 \%$ humid atmosphere of $5 \% \mathrm{CO}_{2}$ in air. The cultures were viewed routinely at 8 days and thereafter for colony formation. Culture time ranged from 8 to 18 days with a mean of 10 days. When sufficient growth had occurred, Colcemid [23] was added to each dish to give a final concentration of 0.1 $\mu \mathrm{g} / \mathrm{ml}$ and the dishes were incubated for a further 4 hours for the accumulation of metaphase cells. Chromosome spreads were then prepared in situ [3]. The culture medium was replaced with the same volume of a warm hypotonic solution composed of 1 part growth medium and 3 parts distilled water and the dishes were reincubated for $30 \mathrm{~min}$ at $37^{\circ}$. Four or five drops of fixative ( 1 part glacial acetic acid to 3 parts methanol) were then added directly into the hypotonic medium. After $5 \mathrm{~min}$, half of this medium-fixative mixture was poured off and replaced by the same volume of fresh fixative. After a further 5 min the mediumfixative mixture was discarded completely and replaced with fresh fixative. This was left for $5 \mathrm{~min}$, whereupon the fixative was poured off and the cells allowed to air dry, often with a little blowing to increase the rate of evaporation. The preparations were hydrolyzed with $5 \mathrm{~N} \mathrm{HCl}$ for $8 \mathrm{~min}$ at room temperature, washed in tap water, stained with $1 \%$ aqueous cresyl violet for $15 \mathrm{~min}$, passed through $70 \%, 95 \%$, and absolute alcohol, and air-dried. After removing the side of the plastic dish, the disc was attached with tape to a glass slide, 51 by $75 \mathrm{~mm}$, and the preparations were viewed under oil immersion microscopy without a mounted coverslip.

As far as possible, three metaphases were analyzed for each colony examined. If the interpretation was not straightforward, additional analyses were under- taken. For each fluid, the chromosome complement of a series of individual colonies was determined and the results were expressed in terms of colonies analyzed rather than cells analyzed.

\section{Results}

The viable cells suspended in the amniotic fluid proliferated as individual colonies when cultured by the method used in this study (Fig. 1). Chromosome preparations were made by in situ processing and thus, for each fluid sample, the karyotype was established by the analysis of a series of discrete colonies. The number of colonies studied per fluid sample ranged from 1 to 89 with a mean of 15 . Overall, an average of 3 colonies/ petri dish was analyzable.

Prenatal chromosome analysis was undertaken for 47 pregnancies from 45 patients. The reasons for their referral are given in Table I. In two cases, the culture failed completely and permission for repeat amniocentesis was not given, while four others, two with inadequate chromosome preparations and two with suspected mosaicism, were successfully repeated. The success rate with a single specimen was $91.5 \%$, somewhat poorer than that recorded by Nadler [15] (96\%), but in keeping with Hsu et al. [6] (92\%), Milunsky et al. [14] (94\%), and Therkelsen et al. [18] (93.5\%). Of the 45 pregnancies in which a diagnosis was made, normal children have been delivered in 43 (25 female, 19 male, including one pair of twins and one $t(\mathrm{DqGq})$ heterozygote), one male was aborted because of the risk of an $\mathrm{X}$-linked recessive disorder and there was one stillborn female. The sex of the infant was correctly predicted in all cases.

In 48 successful cell cultures, $24(50 \%)$ had one or more colonies in which the chromosomes were entirely tetraploid (Table II). The frequency of tetraploid colonies in these cultures ranged from $2 \%$ to $14 \%$ with a mean of $7 \%$. Tetraploid cells also appeared within other colonies but occurred sporadically among the predominantly diploid cell type. These probably arose in vitro from the diploid cells and were discounted in the analysis.

In four of the amniotic fluid samples, there appeared one or two colonies in which all the cells studied showed an aberrant chromosome pattern involving aneuploidy or translocation (Table III). Case 1 had one abnormal colony in which the four analyzable cells showed the same translocation between a chromosome 2 and an $\mathrm{E}$ group chromosome. A repeat amniocentesis was performed and in the second culture 57 


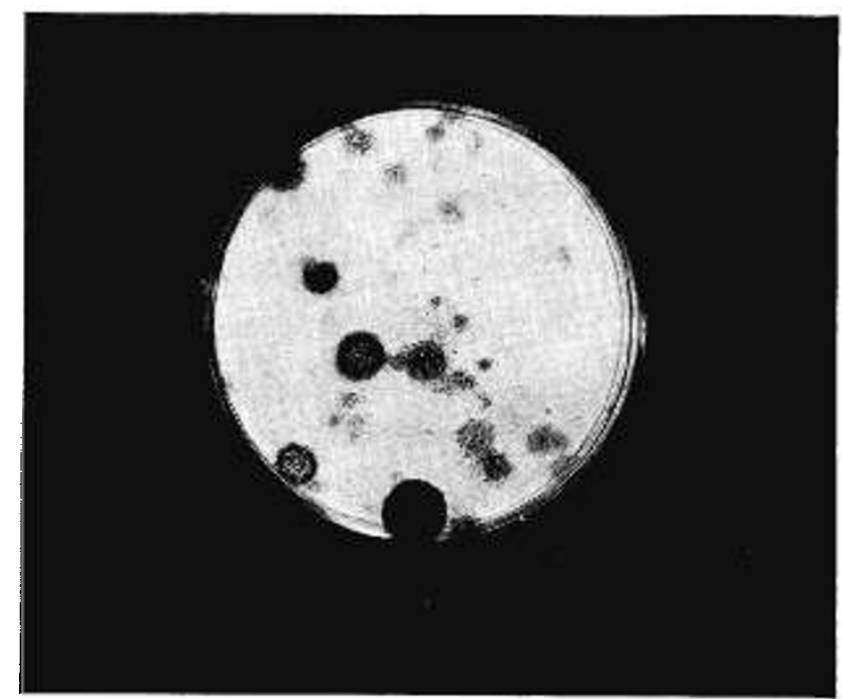

Fig. 1. Appearance of amniotic fluid cell colonies after 14 days of culture. The preparations are heavily stained with crystal violet to enhance visualization.

Table I. Indications for prenatal chromosome analysis in 45 patients

\begin{tabular}{lc}
\hline \multicolumn{1}{c}{ Indication } & No. patients \\
\hline Maternal age $>35$ & 23 \\
Previous trisomic Down's & 10 \\
Translocation carrier & 3 \\
Previous spontaneous abortion & 2 \\
with trisomy & \\
Other chromosomal & 6 \\
X-linked recessive & 1 \\
\hline
\end{tabular}

colonies were studied. Of these, 53 were $46, \mathrm{XX}$ and 4 were tetraploid. There was no evidence of the rearrangement. An apparently normal female infant was delivered and karyotyping by peripheral blood culture showed normal female chromosomes with no indication of a translocation in 100 metaphases analyzed. In case 2 , there were two abnormal colonies. Twenty cells were analyzed in each colony with one consistently showing trisomy $\mathrm{C}$ and the other consistently showing a translocation between a $\mathrm{B}$ and a $\mathrm{C}$ group chromosome. Repeat amniocentesis was not undertaken and subsequently an apparently normal male infant was delivered. Peripheral blood karyotyping showed a normal male chromosome complement with no apparent abnormalities in 100 analyzed cells. Case 3 had one very large abnormal colony in which the 20 cells examined showed trisomy for chromosome 2. A repeat culture was not undertaken. Apparently normal male twins were delivered at term and analysis of 100 metaphases from a peripheral blood culture for each infant revealed a normal male karyotype with no evidence of trisomy 2 . In case 4, there was one large abnormal colony in which the 20 cells analyzed showed trisomy for a $\mathrm{C}$ group chromosome. Repeat amniocentesis was not undertaken and an apparently normal female infant was delivered. It was not possible to confirm the karyotype in this case.

Throughout the series of cases studied, aberrant cells also appeared sporadically within otherwise normal diploid colonies. These were discounted in the analysis inasmuch as their rare and isolated occurrence among normal cells is strongly suggestive of cultural origin.

\section{Discussion}

The procedure used in this study differs from that generally followed. The cells in the fluid were not aggregated by centrifugation nor were the colonies dispersed by trypsinization. In all probability, each colony arose from a single cell or small group of cells that had been suspended in the amniotic fluid at the time of amniocentesis. The possibility that a small number

Table II. Frequency of tetraploid colonies in 48 amniotic fluid cell cultures

\begin{tabular}{cc}
\hline Tetraploid colonies & No. amniotic fluids \\
\hline 0 & 24 \\
$1-5 \%$ & 9 \\
$6-10 \%$ & 12 \\
$10-15 \%$ & 3 \\
\hline
\end{tabular}

Table III. Chromosome analysis of four amniotic fluid cell cultures with entire colonies showing aneuploidy or translocation

\begin{tabular}{crl}
\hline \multirow{2}{*}{ Total colonies studied } & \multicolumn{2}{c}{ Chromosome analysis } \\
\cline { 2 - 3 } & No. colonies & \multicolumn{1}{c}{ Karyotype } \\
\hline Case 1 (33) & 32 & $46, \mathrm{XX}$ \\
& 1 & $46, \mathrm{XX}, \mathrm{t}(2 \mathrm{p}-; \mathrm{Eq}+)$ \\
Case 2 (37) & 33 & $46, \mathrm{XY}$ \\
& 2 & Tetraploid \\
& 1 & $47, \mathrm{XY},+\mathrm{C}$ \\
Case 3 (48) & 1 & $46, \mathrm{XY}, \mathrm{t}(\mathrm{Bq}+; \mathrm{Cq}-)$ \\
& 42 & $46, \mathrm{XY}$ \\
Case 4 (89) & 5 & Tetraploid \\
& 1 & $47, \mathrm{XY},+2$ \\
& 79 & $46, \mathrm{XX}$ \\
& 9 & Tetraploid \\
& 1 & $47, \mathrm{XX},+\mathrm{C}$ \\
\hline
\end{tabular}


of satellite colonies were also present cannot be excluded. Nevertheless, colony analysis reflects more closely the chromosomal status of the original fluid sample. By giving equal emphasis to small and large colonies alike, distortions in the analysis because of over-representation of more vigorously growing cell types is reduced. The occurrence of entire colonies with a constant abnormal karyotype showing tetraploidy, aneuploidy, or translocation must be attributable either to chromosome change very early in culture or to the presence of the abnormal cell type in the amniotic fluid itself.

The degree of diploid-tetraploid mosaicism in amniotic fluid cell cultures is very variable. Walker et al. [19] observed tetraploids in $87 \%$ of cases, with the frequency ranging from $1 \%$ to $100 \%$. Milunsky et al. [13] reported that $66 \%$ of fluids studied showed some degree of tetraploidy which ranged from $4 \%$ to $83 \%$, whereas Therkelsen et al. [18] encountered from $3 \%$ to $27 \%$ tetraploidy in all of the 18 cases investigated. In the present study, only $50 \%$ of the cultures had entirely tetraploid colonies and these never accounted for more than $15 \%$ of the colonies examined. No chromosomally abnormal infants were born in these cases with tetraploid colonies. This corroborates the conclusions of Walker et al. [19] and Milunsky et al. [13], that even a high degree of polyploidy is compatible with the birth of a chromosomally normal offspring and should not be considered a reason for termination. The lower incidence of tetraploidy encountered in the present study may reflect more realistically the degree of tetraploidy in amniotic fluid cells. This contention is supported by the observations of Klinger and Schwarzacher [9] and Schlegel et al. [17] that 10\% of normal amnion is tetraploid.

The occurrence of chromosomally abnormal cell types as a minor component of an otherwise chromosomally normal amniotic fluid cell culture is by no means uncommon. In the present study, 4 of the 47 successfully cultivated amniotic fluid samples showed one, and in one instance two, chromosomally abnormal colonies. Three of these involved trisomy $(47, \mathrm{XY},+\mathrm{C}$; 47, XX, + C; 47,XY, +2) and two involved translocation $(46, \mathrm{XY}, \mathrm{t}(\mathrm{Bq}+; \mathrm{Cq}-) ; 46, \mathrm{XX}, \mathrm{t}(2 \mathrm{p}-; \mathrm{Eq}+))$. Other workers have reported $47, \mathrm{XX},+\mathrm{C}[7], 47, \mathrm{XY},+\mathrm{G}$ [11], and $46, \mathrm{XY},+\mathrm{D},-\mathrm{G}$ [6] karyotypes in amniotic fluid cell cultures with predominantly normal chromosomes. In no instance has the minor aberrant cell type observed in the amniotic fluid been demonstrated in the abortus or neonate and, thus, this "pseudomosaicism" has been ascribed to artifact of tissue culture $[7,11]$. The finding of colonies with a consistent abnormal karyotype in the present study indicates that a single progenitor cell probably gave rise to the entire colony. This suggests that these abnormal cells are not necessarily of cultural origin but may in fact be present in the amnion.

In two of the cases presented here, the abnormal colony was extremely large whereas other colonies in the dish were few and quite small. Conceivably, dispersion of the cells in these dishes with trypsin and reculture before chromosome preparation could have allowed the abnormal cell type to dominate the culture and give the illusion of a chromosomally abnormal fetus. Indeed, Kardon et al. [8] reported a consistently 45, X karyotype in an amniotic fluid culture, but on reculture of amniotic fluid at abortion only a 46,XY karyotype was found. The fetus was concluded to have been a 45,X/46, XY mosaic. However, in this case, overgrowth by the abnormal cell type, in the manner put forward by Mannanal [12] and also described above, provides an alternative interpretation of the findings which is as valid as mosaicism.

Clearly, the frequency with which chromosomally aberrant cell types appear in normal amniotic fluid cell cultures will make prenatal diagnosis of a true mosaic extremely hazardous. Bloom et al. [1] detected $46, \mathrm{XX} / 47, \mathrm{XX},+\mathrm{D}$ mosaicism prenatally which was confirmed by the analysis of fetal tissues obtained by hysterotomy. This further heightens the dilemma of making, what are in reality, intuitive clinical decisions in regard to the significance of chromosomal mosaicism in amniotic fluid cell cultures. In the present study, the recommendation against abortion was, in retrospect, correct, but the case of Bloom et al. [1] confirms the reality of the risks taken.

By the study of a series of individual colonies derived from a specimen of amniotic fluid, as described here, it is hoped that the diagnosis of true mosaicism can be made more securely. From the small number of cases presented it appears that a single abnormal colony, or more than one abnormal colony but with different karyotypes, does not reflect mosaicism in the fetus. However, until more data is available it would seem prudent to undertake a repeat amniocentesis in such cases. If more than one colony has the same abnormal karyotype, and particularly if these are located in different petri dishes and are thus clearly independent in origin, the possibility of true mosaicism must be very high. In this case, a repeat amniocentesis would be essential for confirmation of the findings. In addition, the method for chromosome analysis described here might make interpretation 
much easier in cases such as that described by Epstein et al. [4], in which the fetal cells revealed an unusual chromosomal rearrangement, or that discussed previously by Kardon et al. [8].

\section{Summary}

The occurrence of chromosomal mosaicism in a series of diagnostic amniotic fluid cell cultures is documented. Chromosome preparations were made by in situ processing and for each fluid sample the karyotype was established by the analysis of a series of discrete colonies. The method was $91.5 \%$ successful with a single specimen and the sex of the infant was predicted correctly in all cases.

In $50 \%$ of cultures there was one or more entirely tetraploid colonies but these never accounted for more than $15 \%$ of the colonies examined. No chromosomally abnormal infants were born in these cases and diploid-tetraploid mosaicism should not be considered grounds for termination of pregnancy. In four otherwise normal amniotic fluid cell cultures, there were one or two colonies in which all of the cells studied showed an aberrant chromosome pattern involving aneuploidy or translocation. In no instance was the minor abnormal cell type observed in the amniotic fluid demonstrated to be present in the newborn infant.

The appearance of chromosomally abnormal cell types in normal amniotic fluid cell cultures complicates the prenatal diagnosis of true mosaicism. By karyotype analysis of a series of colonies arising from a specimen of amniotic fluid, the interpretation of chromosomal mosaicism, when present, should be made less ambiguous.

\section{References and Notes}

1. Bloom, A. D., Schmickel, R., Barr, M., and Burdi, A. R.: Prenatal detection of autosomal mosaicism. (In press).

2. Bodensteiner, J. B., ANd Zellweger, H.: Mongolism preventable by amniocentesis: An appraisal of the genetic considerations. Clin. Pediat., 10: 554 (1971).

3. Cox, D. M., AND RAY, M.: Evaluation of cell viability in chromosomally heterogeneous cell populations. Can. J. Genet. Cytol., 13: 484 (1971).

4. Epstein, C. J., Schneider, E. L., Conte, F. A., And Friedman, S.: Prenatal detection of genetic disorders. Amer. J. Hum. Genet., 24: 214 (1972).
5. Gerbie, A. B., Nadler, H. L., and Gerbie, M. V.: Amniocentesis in genetic counseling: Safety and reliability in early pregnancy. Amer. J. Obstet. Gynecol., 109: 765 (1971).

6. Hsu, L. Y. F., Dubin, E. C., Kerenyx, T., and Hirschhorn, K.: Results and pitfalls in prenatal cytogenetic diagnosis. J. Med. Genet., 10: 112 (1973).

7. KAJu, T.: Pseudomosaicism in cultured amniotic fluid cells. Lancet, $i i: 1037$ (1971).

8. Kardon, N. B., Chernay, P. R., Hsu, L. Y., Martin, J. L., AND HurschHorn, K.: Pitfalls in prenatal diagnosis resulting from chromosomal mosaicism. J. Pediat., 80: 297 (1972).

9. Klinger, H. P., AND SChwarzacher, H. G.: The sex chromatin and heterochromatic bodies in human diploid and polyploid nuclei. J. Biophys. Biochem. Cytol., 8: 345 (1960).

10. Kohn, G., And Robinson, A.: Tetraploidy in cells cultured from amniotic fluid. Lancet, $i i$ : 778 (1970).

11. Lee, J. C., Bendel, R. P., And Brooker, D. C.: Aneuploidy in cultured amniotic cells. J. Amer. Med. Ass., 219: 1211 (1972).

12. Mannanal, G. S.: The issue of chromosomal mosaicism in prenatal diagnosis. J. Pediat., 81: 422 (1972).

13. Mrlunsky, A., Arkins, L., And Littlefield, J. W.: Polyploidy in prenatal genetic diagnosis. J. Pediat., 79: 303 (1971).

14. Milunsky, A., Atkins, L., and Littlefield, J. W.: Amniocentesis for prenatal genetic studies. Obstet. Gynecol., 40: 104 (1972).

15. Nadler, H. L.: Prenatal detection of genetic disorders. In: $\mathbf{H}$. Harris and K. Hirschhorn: Advances in Human Genetics, Vol. 3, p. 1 (Plenum Press, New York, 1972).

16. Nadler, H. L., ANd Gerbie, A.: Present status of amniocentesis in intrauterine diagnosis of genetic defects. Obstet. Gynecol., 38: 789 (1971).

17. Schlegel, R. J., Neu, R. L., Leao, J. C., Farias, E., Aspillaga, M. J., AND GARDNER, L. I.: Observations on the chromosomal, cytological and anatomical characteristics of 75 human conceptuses. Cytogenetics, 5: 430 (1966).

18. Therkelsen, A. J., Petersen, G. B., Steenstrup, O. R., JonasSon, J., Lindsten, J., AND ZECH, L.: Prenatal diagnosis of chromosome abnormalities. Acta Paediat. Scand., 61: 397 (1972).

19. Walker, S., Lee, C. L. Y., and Gregson, N. M.: Polyploidy in cells cultured from amniotic fluid. Lancet, $i i: 1137$ (1970).

20. Falcon Plastics, Los Angeles, Calif.

21. Schwarz BioResearch, Orangeburg, N. Y.

22. Microbiological Associates, Bethesda, Md.

23. Ciba Pharmaceuticals, Inc., Summit, N. J.

24. Informed consent was obtained from all persons in this study.

25. This work was supported by the Medical Research Council of Canada, Grant no. MA 4582 and The Children's Hospital of Winnipeg Research Foundation, Inc.

26. Requests for reprints should be addressed to: D. M. Cox, Ph.D., Genetics Department, Health Sciences Children's Centre, 685 Bannatyne Avenue, Winnipeg, Manitoba, R3E OW1, Canada.

27. Accepted for publication February 14, 1974. 